\title{
Endovascular Treatment for Carotid Blowout Syndrome after Radiation: A Case Report
}

Roger Rodrigues*, João Costa, Diogo Roriz, Gabriel Anacleto and Óscar Gonçalves

Department of Angiology and Vascular Surgery, Coimbra University Hospital, Praceta Mota Pinto Av. Bissaya-Barreto, Coimbra, Portugal

\begin{abstract}
Carotid blowout syndrome is one of the most complex bleeding complications that may occur in head and neck cancers patients. The purpose of this paper is to report the clinical manifestations and endovascular management of a case of patient with neck malignancies and a history of radiotherapy. The patient underwent immediate covered stent deployment which resulted in the successful control of bleeding.
\end{abstract}

Keywords: Carotid blowout syndrome; Radiotherapy; Endovascular treatment; Esophageal carcinoma

\section{Introduction}

Carotid Blowout Syndrome (CBS) is a life-threatening complication associated with head and neck cancers (HNC) and its treatment. The manifestations of CBS range from asymptomatic exposure of the carotid arteries to active haemorrhage with hypovolaemic shock [1]. CBS is more frequent in cases of radiation induced necrosis, recurrent tumours, wound complications from neck dissection, or vessel erosion from pharyngocutaneous fistulas. Carotid blowout syndrome (CBS) resulting from radiotherapy alone is an uncommon complication and is usually associated with sudden, catastrophic bleeding [2-4]. The mortality rate was reported to range from $3 \%$ to over $50 \%$ in the literature [5]. Therefore, in a recent meta-analysis, the mortality rate of carotid blowout after re-irradiation in those patients treated by head and neck tumours was as high as $76 \%$ [2]. Direct surgical repair of the ruptured internal carotid artery is often not technically possible due to the difficult anatomy and underlying poor co-morbid status $[5,6]$. Endovascular techniques such as coil embolization and stent grafting offer an alternative to surgical ligation with better patient outcomes $[7,8]$. We describe the successful use of an endovascular approach in a case of emergent rupture of the common carotid artery (CCA) with massive bleeding in a patient with neck malignancies and a history of radiotherapy.

\section{Case Report}

A 75-year-old man with a squamous cell carcinoma of the esophagus having undergone chemotherapy and radiotherapy until January 2017. In March he performed a PET scan that revealed a partial response to treatment. He had also a history of vocal cord cancer treated with total laryngectomy and chemo-radiation in 1987. He was admitted to the emergency room with haematemesis with approximately 1 hour of evolution. The patient was pale, hypotensive and had several episodes of bright red blood coming from his mouth. His initial vital signs included a pulse of $130 \mathrm{bpm}$, blood pressure of $90 / 67 \mathrm{mmHg}$ and an oxygen saturation of $93 \%$ on room air. On exam, a clear and patent trachea stoma was visualized, and her neck revealed broader carotid pulse on the right side without any open wounds. The patient continued with hematemesis during the clinical evaluation. Considering the history of cervical radiotherapy and the presence of esophageal neoplasia, we suspect that neck vessels were involved. An angiogram performed via the right common femoral artery revealed, in the right common carotid artery, contrast extravasation (Figure 1). A $6 \mathrm{~mm} \times 38 \mathrm{~mm}$ Atrium ADVANTA V12 ${ }^{\mathrm{mm}}$ balloon expandable covered stent was deployed in the right common carotid artery. After the deployment contrast extravasation was still demonstrated (Figure 2) so a second Atrium ADVANTA V12 ${ }^{\mathrm{m}}$ with the same size was placed

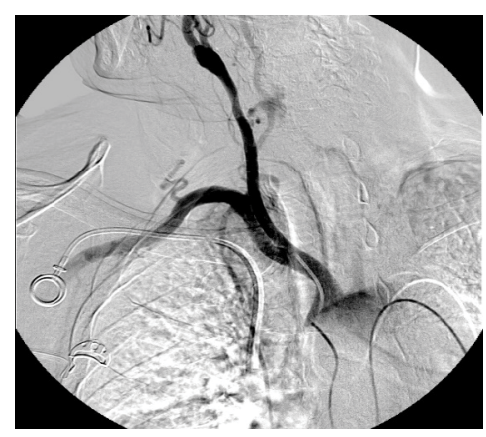

Figure 1: Contrast extravasation in the right common carotid artery.

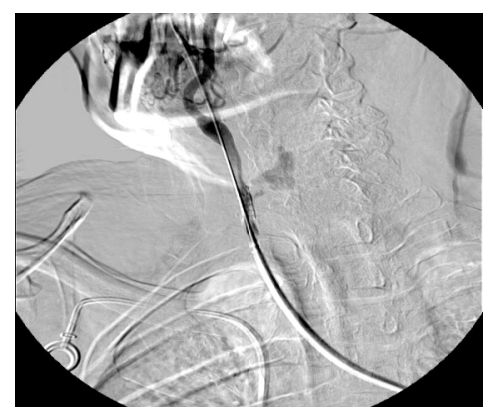

Figure 2: Self-expandable endoprothesis was deployed in the right common carotid artery. After the deployment contrast extravasation was still demonstrated.

*Corresponding author: Roger Rodrigues, Department of Angiology and Vascular Surgery, Coimbra University Hospital, Praceta Mota Pinto/Av. Bissaya-Barreto, 3000-075 Coimbra, Portugal, Tel: 351918400967; Email: roger.cc@hotmail.com

Received November 06, 2017; Accepted November 28, 2017; Published November 30, 2017

Citation: Rodrigues R, Costa J, Roriz D, Anacleto G, Gonçalves O (2017) Endovascular Treatment for Carotid Blowout Syndrome after Radiation: A Case Report. J Cancer Sci Ther 9: 727-729. doi:10.4172/1948-5956.1000499

Copyright: () 2017 Rodrigues R, et al. This is an open-access article distributed under the terms of the Creative Commons Attribution License, which permits unrestricted use, distribution, and reproduction in any medium, provided the original author and source are credited. 
immediately superior to the previous with successfully bleeding control (Figure 3). A cranial CT was performed thereafter which reveal no recent ischaemic lesions (Figure 4). The patient was discharged 10 days later without neurological deficit or recurrent bleeding.

\section{Discussion}

Carotid blowout syndrome is one of the most complex bleeding complications that may occur in HNC patients. It Is usually a lifethreatening complication, and is accompanied with unexpectedly massive bleeding and high mortality/morbidity rates $[9,10]$. Short and long-term effects of radiation over arteries have been reported. A total radiation doses of 40 Gy over a 10-day duration could induce damage to the vasa vasorum of large arteries and it might be related to the rupture of great arteries [11]. Free radicals produced by radiation were also found to cause thrombosis and obliteration of vasa vasorum, adventitial fibrosis, premature atherosclerosis, and the weakening of the arterial wall in the histological examination of resected carotid arteries [5,1113]. Some authors suggest also a role of infections in CBS and the relation of bacterial inflammation as a cause of vasa vasorum thrombosis, and secondary arterial wall damage. Neck surgery is another significant factor related to CBS, because this kind of surgeries could compromise the nutrition of the carotid artery during cervical nodes resection, resulting in injury to the adventitial layer, and this deleterious effect occurs independently of radiation $[6,14]$. In the HNC population with previous surgery or radiotherapy, a high index of suspicion must be maintained for CBS in patients presenting with any recent history of oral bleeding or haemorrhaging from an exposed neck wound [11]. The incidence of cerebral complications in patients affected by CBS, are up to $87 \%$ when hypotension is present at the time of ligation compared to $28 \%$ in normotensive patients [13]. In patients who survived an acute episode of carotid blowout, the neurological sequela reported was from $16 \%$ to $50 \%$ [6]. Because hypotension is a major risk factor for stroke in these patients, homodynamic stabilization and airway protection were our first priorities. A recent study found out that patients with

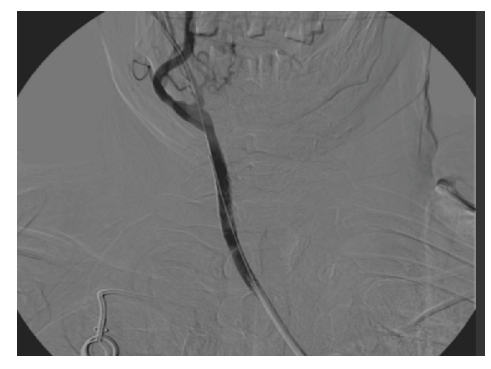

Figure 3: Control angiogram without contrast extravasation.

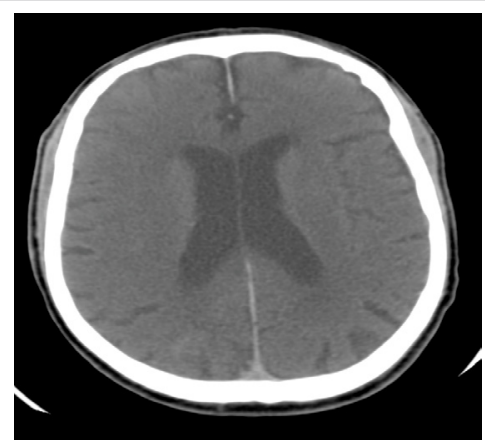

Figure 4: Cranial CT allowed the exclusion of recent vascular ischemic or haemorrhagic changes. carotid blowout that underwent surgical intervention had a higher neurologic complication rate and mortality rate when compared with those patients that underwent an endovascular approach [15]. Current evidence shows that there was no significant difference in technical and haemostatic outcomes between the reconstructive and deconstructive endovascular methods because permanent vessel occlusion resulted in higher immediately cerebral ischemia and stent grafting induced the more potentially delayed complications, such as infection, rebleeding, and stent thrombosis [4,7]. According to some authors when the lesion involves branches of the external carotid artery, destructive techniques are usually used with coil embolization of these vessels. Those involving the main trunk of the carotid artery received either deconstructive treatment or constructive treatment according to the result of a balloon occlusion test (BTO) which evaluates blood supply from intracranial collateral circulation. In some institutions constructive treatment is only applied for patients with the incomplete circle of Willis, precluding an occlusion test, or intolerant BTO, that when carotid occlusion poses an unusually high risk of neurologic morbidity [16]. In the present case, we excluded a BTO approach, as the patient was hemodynamically instable, it was a lifesaving situation, and we decided for the placement of a covered stent on the common carotid artery to avoid wasting more time. The immediate results are appealing, however, as previously stated, the risk of a new haemorrhagic event is unpredictable, and the consequences may be disastrous.

\section{Conclusion}

In the present case, the endovascular management of CBS of the common carotid artery had high technical success and achieved immediate haemostasis. It has been suggested that covered stents are useful for the initial control of carotid bleeding, but they are also associated with delayed complications such as rebleeding, thrombosis, infection and occlusion. A tight follow up is indicated to manage the high rebleeding rate.

\section{References}

1. Chaloupka JC, Putman CM, Citardi MJ, Ross DA, Sasaki CT (1996) Endovascular therapy for the carotid blowout syndrome in head and neck surgical patients: diagnostic and managerial considerations. AJNR Am J Neuroradiol 17: 843-852.

2. McDonald MW, Moore MG, Johnstone PA (2012) Risk of carotid blowout after reirradiation of the head and neck: A systematic review. Int J Radiat Oncol Biol Phys 82: 1083-1089.

3. Cohen EE, Rosine D, Haraf DJ, Loh E, Shen L, et al. (2007) Phase I trial of tirapazamine, cisplatin, and concurrent accelerated boost reirradiation in patients with recurrent head and neck cancer. Int J Radiat Oncol Biol Phys 67: 678-684.

4. Shah H, Gemmete JJ, Chaudhary N, Pandey AS, Ansari SA (2011) Acute lifethreatening hemorrhage in patients with head and neck cancer presenting with carotid blowout syndrome: Follow-up results after initial hemostasis with covered-stent placement. AJNR Am J Neuroradiol 32: 743-747.

5. Roh JL, Suh DC, Kim MR, Lee JH, Choi JW, et al. (2008) Endovascular management of carotid blowout syndrome in patients with head and neck cancers. Oral Oncol 44: 844-850.

6. Upile T, Triaridis S, Kirkland P, Archer D, Searle A, et al. (2005) The management of carotid artery rupture. Eur Arch Otorhino-laryngol 262: 555-560.

7. Powitzky R, Vasan N, Krempl G (2010) Carotid blowout in patients with head and neck cancer. Ann Otol Rhinol Laryngol 119: 476-484.

8. Zussman B, Gonzalez LF, Dumont A, Tjoumakaris S, Rosenwasser R, et al (2012) Endovascular management of carotid blowout. World Neurosurg 78: 109-114.

9. Katras T, Baltazar U, Colvett K, Rush D, Dunn J, et al. Radiation-related arterial disease. Am Surg 65: 1176-1179. 
Citation: Rodrigues R, Costa J, Roriz D, Anacleto G, Gonçalves O (2017) Endovascular Treatment for Carotid Blowout Syndrome after Radiation: A Case Report. J Cancer Sci Ther 9: 727-729. doi:10.4172/1948-5956.1000499

10. Kock WM (1993) Complication of surgery of the neck. In: Eisele D (ed), Complication in head and neck surgery, Mosby, St. Louis, USA. pp. 393-413.

11. McCready RA, Hyde GL, Bivins BA, Mattingly SS, Griffen WO Jr (1983) Radiation-induced arterial injuries. Surgery 93: 306-312.

12. Huvos AG, Leaming RH, Moore OS (1973) Clinicopathologic study of the resected carotid artery. Analysis of sixty-four cases. Am J Surg 126: 570-574.

13. Moore OS, Karlan M, Sigler L (1969) Factors influencing the safety of carotid ligation. Am J Surg 118: 666-668.
14. Chen YJ, Wang CP, Wang CC, Jiang RS, Lin JC (2015) Carotid blowout in patients with head and neck cancer: Associated factors and treatment outcomes. Head Neck 37: 265-272.

15. Kim HS, Lee DH, Kim HJ, Kim SJ, Kim W, et al. (2006) Life-threatening common carotid artery blowout: Rescue treatment with a newly designed self-expanding covered nitinol stent. Br J Radiol 79: 226-231.

16. Wan WS, Lai V, Lau HY, Wong YC, Poon WL et al. (2011) Endovascular treatment paradigm of carotid blowout syndrome: review of 8-years' experience. Eur J Radiol 82: 95-99. 